\title{
Advances and challenges in the implementation of strategic adaptive management beyond the Kruger National Park - Making linkages between science and biodiversity management
}

\author{
Authors: \\ Angela Gaylard ${ }^{1}$ \\ Sam Ferreira ${ }^{2}$ \\ Affiliations: \\ ${ }^{1}$ Savanna Research Unit, \\ Conservation Services, South \\ African National Parks, \\ Garden Route Regional \\ Office, Knysna, South Africa \\ ${ }^{2}$ Savanna Research Unit, \\ Conservation Services, South \\ African National Parks, \\ Skukuza, South Africa \\ Correspondence to: \\ Angela Gaylard \\ Email: \\ angela.gaylard@sanparks.org \\ Postal address: \\ PO Box 3542, Knysna 6570, \\ South Africa \\ Dates: \\ Received: 24 May 2010 \\ Accepted: 17 Mar. 2011 \\ Published: 13 May 2011 \\ How to cite this article: \\ Gaylard, A. \& Ferreira, \\ S., 2011, 'Advances \\ and challenges in the \\ implementation of strategic \\ adaptive management \\ beyond the Kruger National \\ Park - Making linkages \\ between science and \\ biodiversity management', \\ Koedoe 53(2), Art. \#1005, \\ 8 pages. doi:10.4102/koedoe. \\ v53i2.1005
}

\section{(C) 2011. The Authors.} Licensee: OpenJournals Publishing. This work is licensed under the Creative Commons Attribution License.
South African National Parks (SANParks) makes use of strategic adaptive management (SAM) to achieve its primary mandate of biodiversity conservation. This involves an iterative adaptive planning, management and review cycle to ensure appropriate alignment of stakeholder values with conservation objectives, to address the uncertainty inherent in complex socialeconomic-ecological systems and to learn explicitly whilst doing so. Adaptive management is recognised as the most logical framework for continuous improvement in natural resource management; nevertheless, several challenges in its implementation remain. This paper outlined these challenges and the various modifications to SANParks' adaptive planning and management process that have emerged during its development. We demonstrated how the establishment of a regular Science-Management Forum provides opportunities for social colearning amongst resource managers and scientists of a particular park, whilst providing other positive spin-offs that mature the SAM process across the organisation. We discussed the use of particular conceptual constructs that clarify the link between monitoring, management requirements and operational endpoints, providing the context within which Thresholds of Potential Concern (TPCs) should be set, prioritised and measured. The evolution of the TPC concept was also discussed in the context of its use by other organisations, whilst recognising its current limitations within SANParks. Finally, we discussed remaining implementation challenges and uncertainties, and suggested a way forward for SAM.

Conservation implications: This paper outlined practical methods of implementing SAM in conservation areas, beyond what has already been learnt within, and documented for, the Kruger National Park. It also highlighted several implementation challenges that prove useful to other conservation agencies planning to adopt this approach to managing complex ecosystems.

\section{Introduction}

South African National Parks (SANParks) makes use of an adaptive planning process to ensure that the principles of strategic adaptive management (SAM) and the managing of its parks conform to legislation as well as to its own mandates, values and organisational structure (Rogers \& Sherwill 2008). The planning process is adaptive because it cycles sequentially, but often iteratively, through its major development phases. SANParks' adaptive planning process originated along with the development of SAM in the Kruger National Park (KNP) in the late 1990s (Biggs 2003). Attempts to implement the approach in the other national parks have met with various extents of success since the mid-2000s (see Biggs et al. 2011; Ferreira et al. 2010). These attempts followed the McKinsey Report (McKinsey \& Company 2002), which highlighted the lack of a formal biodiversity policy or management plans for most of the parks under SANParks' management authority (Rogers \& Sherwill 2008). Such policies are now a requirement under new national legislation for protected areas and the conservation of biodiversity.

Implementing this legislative requirement carries significant challenges for a variety of reasons. Included in these are the uncertainty, expectations and preferences inherent in using adaptive management (Cundill \& Fabricius 2009), and, in particular, Thresholds of Potential Concern (TPCs), when managing complex social-economic-ecological systems (Biggs et al. 2011; Jacobson et al. 2006; Rogers, Roux \& Biggs 2000; Venter et al. 2008). Disjuncts between the understanding of scientists and conservation practitioners (specifically rangers and park managers, henceforth referred to as managers) in terms of how systems may function often leads to inertia in management decisions (Duncan \& Wintle 2008; Rogers 2003) and hence a great deal of frustration for conservation agencies trying to deliver their mandate. 
In this paper, we address this challenge and illustrate how regular science-management interactions can generate positive spinoffs that mature SAM across the organisation. This includes the explicit use of particular conceptual constructs and supplementary tools that enable the development of joint mental models between scientists and managers. We will also demonstrate how the latter, in turn, has clarified the links between monitoring, management requirements and operational endpoints, and thus provide the context within which TPCs should be set (see Biggs et al. 2011), prioritised and measured. Finally, we reflect on some of the implementation challenges faced by SANParks and consider the areas that still require development to take SAM forward.

\section{Bridging the science- management gap}

\section{Linking scientists and managers by creating a forum for developing a shared rationale}

Implementing SAM in any South African national park under SANParks' management authority begins with an adaptive planning process involving facilitated stakeholder meetings, in which a vision and mission, as well as high level objectives are jointly agreed upon (Rogers \& Sherwill 2008). Thereafter, this broad values-based vision is translated into a fully fledged objectives hierarchy that documents the sequential reasoning of these values into science-based system outcomes (Rogers \& Sherwill 2008). Decision-making towards achieving these outcomes is based on the setting and subsequent monitoring of the TPCs that define the acceptable limits of change in ecosystem or biodiversity composition, structure and function (Biggs 2003). Finally, it is essential that there is reflection at each step, in order to ensure learning (Cundill \& Fabricius 2009).

Whilst SANParks' application of SAM originated in the $\mathrm{KNP}$, several modifications have emerged as a consequence of its implementation in other national parks. An early and far-reaching example of such a modification was the establishment of a Science-Management Forum (SMF) for each park. SMFs are regular meetings of groups of SANParks scientists and managers, with the primary aim being to provide a platform for meaningful interaction regarding conservation issues. The adaptive planning process requires technical input once the high level objectives have been compiled along with stakeholders. The SMFs therefore present an opportunity for scientists and managers to provide this technical input, working their way through the various stages of their park's adaptive management cycle after the preliminary stakeholder meetings. Consequently, SMFs also provide opportunities for essential discourse amongst scientists and managers about the practical implications of SANParks' recent paradigm shift towards a complex systems approach to conservation (Rogers 2003). Nevertheless, this paradigm shift has been only a recent occurrence and many managers are still reluctant to relinquish the agriculturally based conservation practices of their training and accept the uncertainty inherent in managing the complex ecosystems expounded by scientists (Rogers et al. 2000). Yet managers have a wealth of valuable 'on the ground' knowledge and practical experience of feasible management actions. A critical function of SMFs is therefore to establish regular interactions between scientists and managers, in which they can share their perspectives and develop a shared rationale that can be used to meaningfully proceed with the adaptive management process.

It is during this process with the SMFs that several additions or modifications have developed that have proved very constructive to the adaptive planning and management process. We outline these below and summarise their benefits for SAM.

\section{Revisiting the objectives hierarchy to ensure that it is linked to management concerns}

Once the high level objectives have been set with the involvement of stakeholders, the technical details for unpacking each objective to create an objectives hierarchy is left to the conservation practitioners, that is park managers and scientists. Lower levels of management are not always required to be present at the stakeholder meetings where the vision, mission, vital attributes and high level objectives are derived. However, it is essential that all members of the SMF have had an opportunity to articulate their values, because these components are the direct translations of stakeholder values into the top tiers of the objectives hierarchy. Agreement at this level of the adaptive planning process prevents conflicts lower down the objectives hierarchy at the levels where these managers have to operate.

If the managers have not been involved in the stakeholder meetings, it is particularly important that they are provided with an opportunity to list all of their management concerns. This contributes significantly towards buy-in by these managers, whilst also ensuring that the scientists become aware of the particular suite of issues faced by these managers on the ground. Similar concerns are then grouped into what have become known as 'concern themes' and cross-checked against the objectives hierarchy. Apart from ensuring that no important issues are omitted from the objectives hierarchy, this exercise is particularly useful for scientists and managers to gauge the alignment of their own concerns (which, to a large extent, represent their values) against one another, and against the values of the park's stakeholders.

Once the concern themes have been listed, the managers are asked to prioritise them according to the urgency with which they feel each concern needs to be addressed. Concern themes most often receiving high priority involve the adverse effects of herbivory, predation and degradation such as erosion and alien plant infestation. Importantly, these concerns are articulated in terms of ecosystem processes, in line with SANParks' paradigm shift away from its previous species focus. 


\section{Linking the objectives hierarchy with TPCs, monitoring and research}

Following a complex systems approach requires the recognition that ecosystems need to fluctuate in order to maintain their resilience (Jacobson et al. 2006; Pickett, Kolasa \& Jones 2007). SAM makes use of upper and lower TPCs to quantify how much to allow a system to fluctuate before managers should become concerned that it is about to change into an undesirable state (Biggs 2003).

Once concern themes have been identified and prioritised, the next step is to identify TPCs for each. Several factors challenged the derivation of these endpoints at the nonKNP SMFs. Firstly, there were fewer (internal and external) scientists present with knowledge of the particular ecological system in smaller parks. Secondly, fewer staff members present were familiar with the process of adaptive planning and management. Thirdly, there was less familiarity with the concepts of flux and resilience and, lastly, the managers present largely still focused on managing species rather than ecosystem processes. Consequently, what may have been intuitively obvious to those well-versed in the decade or so of TPC development in the KNP (i.e. the linkage between lower level objectives and operational endpoints and TPCs) was often conspicuously absent in the SMFs held in other parks. In the absence of such a linkage, the indicators, endpoints, and hence TPCs, are either difficult to identify or become disjointed from the mechanisms underlying the ecological processes involved.

A key modification of the SAM process has developed through its implementation beyond the KNP to overcome this disjunct between higher and lower level planning. This modification involves unpacking the particular concerns related to each of the lower level objectives, identifying the ecological processes underlying these concerns and then exploring the mechanism and its drivers and modulators jointly with scientists and managers during the SMFs. This is achieved explicitly by making use of a framework to extract a joint science-management understanding of these mechanisms (see Lindenmayer \& Likens 2009). The use of a framework cooperatively exposes the mental models of scientists and managers, capitalising on the diverse experience and knowledge of both groups. In addition, in the true spirit of adaptive management, the framework acts as a knowledge management system, to which improvements to conservationists' existing understanding can be added over time, ensuring explicit learning (Gaylard, Cadenasso \& Pickett in press).

A multitude of frameworks exist for compiling conceptual models of ecological processes (Cundill \& Fabricius 2009). The ultimate premise of SANParks' objectives hierarchies is the maintenance of a 'desired state' (or set of conditions allowing a certain amount of flux), which meant that our need for a framework resonated strongly with the framework developed by Pickett, Cadenasso and Benning (2003). Their framework explores the creation of, and response to, heterogeneity, with its basic building blocks representing a change from one (desirable) condition to another (undesirable condition; see Figure 1).

This naturally poses the question of what brings about the change (i.e. the agent or driver), from which point any other factors that members of the SMF understand or hypothesise to influence the state change (through their action on the driver, i.e. modulators) can be incorporated into the conceptual framework. Once the conceptual model is complete, at least according to the joint understanding of the SMF, the drivers and modulators are easily identifiable from the resultant diagram of the mechanism. The drivers (ideally) or modulators are the practical translation of the management objective into a measurable TPC because, through the use of the framework, they provide the link between the objective and the required TPC. The members of the SMF quantify the TPC using their own knowledge and expertise, and within the context of the values articulated through the objectives hierarchy. Scientists (within and external to SANParks) are then consulted to comment on and/or fine-tune these quantifications.

It is important that the facilitator incorporates the aspect of scale into the discussion of the mechanism in question, because focusing on just one scale might obscure important controlling processes at other scales (Cundhill \& Fabricius 2009). Moreover, identification of the scale at which, ultimately, the TPC's indicator will be measured is that at which the mechanism operates. In addition, in order to quantify the upper and lower levels of the TPC between which the particular component of the system will be allowed to flux, the SMF assesses the risk to the system should the TPC be exceeded. A very useful construct for balancing 'risk tolerant' versus 'risk averse' notions is use of the concept of 'reversibility' (i.e. how reversible is the process?). Processes that are irreversible or would take much longer to recover tend to have risk averse TPCs (i.e. they are not allowed to flux very widely), whereas TPCs for processes that can easily be reversed (e.g. supplementing game after predation has reduced prey biomass) may be allowed to have wider limits of tolerance. Risk assessments have also been used by SANParks to prioritise objectives (see Box 1) and, more recently, to evaluate the trade-offs between various management options to achieve a desired objective.

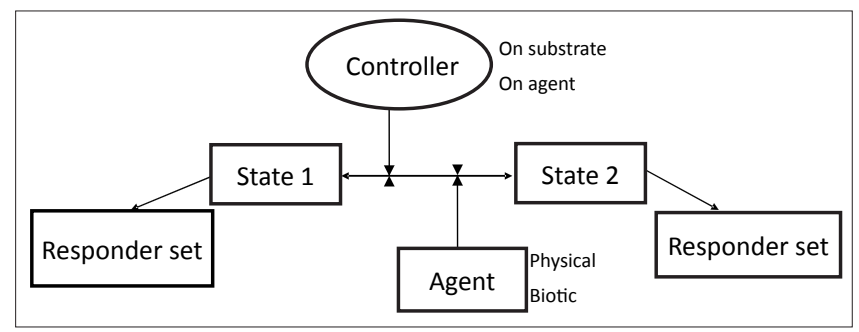

FIGURE 1: Pickett et al.'s (2003) framework for understanding the generation of and responses to heterogeneity, used during the process of unpacking concerns in Science-Management Forum meetings. 
Risk assessment is part of the process of enterprise-wide risk management, which has become a key aspect in the focus on corporate governance over the last number of years. This assessment process has been developed to compare very different and often disparate risks. By making certain modifications to its application, South African National Parks (SANParks) is currently experimenting with the risk assessment process as a way of prioritising park objectives in a nuanced way that effectively supports decision-making. This modified process or comparative risk assessment (CRA) is applied towards the end of the adaptive planning, once the park objectives have been decided upon. None of these objectives are challenged in the sense that they can be removed from the list of objectives. In other words, it is accepted that they are all valid and require attention and implementation, but the modified CRA process helps decide whether new additional effort or resources should be directed towards particular objectives and actions regarding other objectives simply maintained or sometimes downscaled with acceptable attendant risk. Without such a process, park managers have a list of, for example, eight major objectives, with champions for each of these often feeling that that the objectives for which they are responsible deserve at least equal urgency and at least an eighth of the resourcing. However, this technique allows group participation in a transparent process, which tends to build a shared rationale around prioritisation and the allocation of resources.

The key modification is a particular emphasis, if each objective fails, on what potential impact that will have on the park vision and mission. It requires that the 'failure' of each objective is re-articulated as a risk and a narrative generated as to what the situation might look like then. This is usually calculated on a 15 year time horizon and we began with a 'business-as-usual' scenario (in other words, conditions continue roughly as they are now). We soon realised that at least another scenario is useful, namely a 'worst case scenario', and possibly further scenarios.

The table below lays out the basic process:

\begin{tabular}{|c|c|c|c|c|c|c|}
\hline $\begin{array}{l}\text { Risk associated with } \\
\text { failure of ... }\end{array}$ & $\begin{array}{l}\text { Impact on park } \\
\text { vision and mission } \\
\text { if objective is not } \\
\text { achieved (rated 1-4) }\end{array}$ & $\begin{array}{l}\text { Likelihood that risk } \\
\text { realises in next } 15 \\
\text { years (rated 1-4) }\end{array}$ & $\begin{array}{l}\text { 'raw score' is product } \\
\text { of impact X chance } \\
(1-16)\end{array}$ & $\begin{array}{l}\text { How effective are } \\
\text { current actions in } \\
\text { controlling this risk } \\
\text { and what resources } \\
\text { are used to do so? }\end{array}$ & $\begin{array}{l}\text { Is this level of risk } \\
\text { control deemed } \\
\text { acceptable i.e. 'within } \\
\text { park risk appetite' } \\
\text { (yes or no) }\end{array}$ & $\begin{array}{l}\text { How effective could } \\
\text { risk abatement be } \\
\text { if improved? What } \\
\text { would this take in } \\
\text { resourcing? }\end{array}$ \\
\hline \multicolumn{7}{|l|}{ Objective 1} \\
\hline \multicolumn{7}{|l|}{ Objective 2} \\
\hline \multicolumn{7}{|l|}{ Objective 3} \\
\hline etc ... & & & & & & \\
\hline
\end{tabular}

The evaluation can be done on a quick 'round table, first estimate' basis by a variety of park personnel or even a wider stakeholder group. In our experience, it is remarkable how similar such subjective scores (in the 'Impact' and 'Likelihood' columns) turn out to be from persons with different viewpoints or tasks in the organisation. So far we have decided not to 'numericise' the answers to the questions in the two 'How effective' and 'At what cost' columns, but essentially these tend to be answered as 'very high', 'high', 'medium', 'low', or 'not/none'. If detailed data are available on some themes, perhaps from business analyses or monitoring results, these can be presented as an improvement on intuitive evaluations. Over time it is good to strive towards this better evidence base, with the proviso that narrow data should not be allowed to cloud good wider judgement. Although the 'raw scores' (product of potential impact should the risk materialises X likelihood of occurrence) are very instructive; the objectives associated with the higher 'raw score' are sometimes not ones towards which the most effort is directed. This is because of clear insight offered by the right hand columns - for instance an objective-risk with a high 'raw score' may already be well contained with medium cost, whereas it may be clear to all that the only way to raise the effectiveness to excellent might be at great cost. The group may then realise in a consensual way that far greater 'bang for buck' can be obtained by using any additional resources elsewhere in the objective profile. The decision on where exactly they might be most profitably be used is also assisted by this assessment.

There are several fine-tuning issues we have encountered in the early use of this technique (for instance, the level at which objectives need to be split or bundled to be meaningfully assessed and whether or not vision and/or mission elements need to be dissociated or viewed together when the impact thereon is considered), but our experience is generally positive and we are hopeful that the technique gives us added value in a sorely needed dimension. It is almost as though risk is a common currency which can assist with decision-making on allocation of resources between say refurbishment of tourist infrastructure, upgrading of IT equipment, a new research project, and enhancement of security to protect endangered biota.

Source: Written by Cillie Malan and Harry Biggs

If there is consensus that there are no practical issues with the monitoring, the measurement of the quantified TPC is incorporated into the monitoring programme, which is developed in parallel to this process. This ensures that all monitoring is linked explicitly to TPCs at each level of the objectives hierarchy (see Ferreira et al. 2011). The only exception to this is what SANParks scientists refer to as 'background' data, which is data used to interpret models of how the system works. These data can be of two distinct types, (1) factors that we have no control over or cannot do anything about (e.g. climate) and (2) factors that we do have control over but, in themselves, are not necessarily drivers (e.g. park-wide animal numbers when they are not high enough to act as modulators). Monitoring data should be constantly checked against the TPCs and tabled at SMFs if they are exceeded, or predicted to be exceeded. A TPC maintenance system (Biggs 2003) then guides the SMF through the process of acting on the exceeded TPC.

Unpacking a concern in this way is a key modification of the SAM process, providing four critical benefits aside from the common understanding to which we have already referred. Firstly, it provides clear guidance in terms of what to manage in order to address the park's objectives. It thus has direct management implications and provides transparent and mutually agreed upon directions for action. In fact, it is sensible to set such 'decision' TPCs (see Martin et al. 2009) based on the modulators of the mechanisms involved. Secondly, this will remove some of the unpredictability and, most importantly, the subjective setting of a TPC solely based on outcome measures such as number of species (see Biggs et al. 2011, for the prediction value judgements that need to be made). Thirdly, the unpacking of a concern provides clear directions about what to measure, as well as the justification for this action. Unpacking of concerns inadvertently imposes prioritisation, because, often, the unpacking exercise identifies perceived concerns for which sometimes conservationists simply cannot do anything about at the park level. Climate change is a good example of this - although monitoring may confirm changing climate, there is little that park managers themselves can do to reverse the trend and hence this concern is ranked lower.

An additional fundamental spinoff of using a framework in this way is that the process forces managers and scientists to expose their various mental models to one another. The joint mental model that emerges therefore recognises the managers' instinctual knowledge, as well as the scientists' empirical or theoretical knowledge, combining them to create a rigorous, yet practical means of dealing with real 
management concerns. Moreover, the compilation of such conceptual models exposes knowledge gaps, information which can then be used to direct research and monitoring.

\section{Case studies: Unpacking concerns to identify the linkages between the objectives hierarchy and TPCs}

Although to date, the process of unpacking concerns has been confined largely to biodiversity issues, Table 1 illustrates attempts to apply it within the areas of SANParks' other core businesses: stakeholders and tourism. As such, we provide three examples of the outcomes of unpacking a concern using the process discussed in the previous section (Table 1).

The first example relates to a typical concern regarding a biodiversity objective, the key mandate of SANParks. The concern is over the loss of particular plant species in the Addo Elephant National Park as a result of elephant impacts. In this example, elephants are the driver of loss of plant species, but unpacking the mechanism reveals that water provision homogenises the elephants' use of space, causing the animals to use landscapes more intensely. As such, individual plants are subjected to more regular foraging, with less time to recover before being visited by elephants again. The extent or rate of this homogenisation is modulated by elephant density, becoming more extensive or rapid with higher elephant densities, resulting in a high risk to the ecosystem because recovery is slow. Hence, the measurement indicator is identified as the elephants' use of space, and how this is related to their density. This case study illustrates how unpacking the concern facilitates the definition of how the particular problem is created. In this case, dealing with the problem requires a change in water distribution long before managers target reductions in abundances of megaherbivores.

The second example that we unpacked (Table 1) relates to how stakeholders affected SANParks' achievement of its suite of strategic objectives. The concern was over the influence of a bad relationship between Augrabies National Park and its stakeholders, on the park's ability to carry out certain activities nearby such as anti-poaching. Unpacking this concern revealed various sources of stakeholder misconceptions about SANParks and, hence, ways of establishing a better relationship with them. Explicit measures of the Park Forum and other community meetings were then identified to track whether and/or how stakeholder perceptions were changing through pro-active engagement activities with stakeholders. This case illustrates how the unpacking of a mechanism at a social level is analogous to unpacking a biodiversity concern. The mechanism, as well as how to address the concern and measure it, is defined in much the same way as with the previous example.

The final example addresses the third pillar of SANParks' strategic objectives: providing benefits to people, in this case through the experience of tourism (Table 1). This example addresses a tourism concern about lack of game observations by visitors to Marakele National Park. Unpacking the mechanism revealed that viewing game was dependent on whether game and tourists were at the same place at the same time, which was constrained by the existing road network and the timing of game drives. Monitoring should therefore be focused on tourists' spatial use of this infrastructure over time, related to large mammal space use. Unpacking this concern revealed that the tacit assumption of increasing game densities to improve a tourist product was not valid, and addressing the concern required a more nuanced approach involving spatial and temporal considerations. This example illustrates that the process does allow for incorporating uncertainty, because, in this instance, the risk component is not clearly understood.

Whilst the three examples represent very different kinds of concerns, the unpacking approach suggested here serves to illustrate how it may greatly enable the generation of common understanding and outcomes within the mandate of a conservation agency.

\section{Evolution of the TPC concept}

Perhaps the most significant area of TPC development within SANParks has therefore been the use of the framework described above. This framework has allowed for the formation of important linkages between the objectives hierarchy and appropriate TPCs by unpacking the mechanisms and modulators that create particular management concerns. Practical experiences in the SMFs have demonstrated how this can also reduce conflict between members of the SMF who hold different viewpoints, thereby easing decision-making and improving our understanding of the system.

There are several examples of rigorously determined biophysical TPCs for the KNP, particularly regarding those for fire (Van Wilgen et al. 2003). However, beyond the KNP there has been a greater focus on ensuring that links are made with objectives, to ensure that appropriate TPCs are identified for a particular objective. Having established these links, there is now a need to focus on the quantification of these TPCs for other parks. Yet there is also room for developing the conceptual basis of TPCs further (Duncan \& Wintle 2008). For example, setting directionality as a prerequisite of a TPC is the central tenet of revisiting TPCs in the SANParks context (Ferreira et al. 2011). Directionality can generalise the applicability of TPCs across parks, because well protected parks can have TPCs for which the rate of change in a measure centres on zero, whilst that for degraded parks centres away from zero. Directionality also generalises across ecological, social, economical and financial spheres (Biggs et al. 2011), a property that bodes well for the social learning required in adaptive management (Cundhill \& Fabricius 2009).

In addition, because TPCs are based on varying degrees of uncertainty, resource managers new to SAM are still uncomfortable with their use (Duncan \& Wintle 2008). It is therefore critical that the development process moves towards making TPCs more tangible to resource managers to avoid an implementation crisis (Rogers 2003). We suggest 
TABLE 1: Three case studies of different types of concerns unpacked in three different national parks in South Africa.

\begin{tabular}{|c|c|c|c|}
\hline \multirow[t]{2}{*}{ Elements to identify when unpacking concerns } & \multicolumn{3}{|c|}{ Case studies } \\
\hline & Addo Elephant National Park & Augrabies Falls National Park & Marakele National Park \\
\hline Concern type & Loss of plant species & $\begin{array}{l}\text { Stakeholder relationships impact on } \\
\text { other park activities }\end{array}$ & $\begin{array}{l}\text { Greatly reduced tourism experience of a } \\
\text { concessionaire }\end{array}$ \\
\hline Concern driver & Mega-herbivores & Stakeholder perceptions & Large mammals \\
\hline Concern mechanism & $\begin{array}{l}\text { Water provision, followed by density } \\
\text { of mega-herbivores homogenise space } \\
\text { use, resulting in more intense use of the } \\
\text { landscape. Individual plants experience } \\
\text { more regular foraging with shorter times } \\
\text { to recover. Selective feeding by mega- } \\
\text { herbivores has changed because certain } \\
\text { plant species are no longer there or } \\
\text { scarce, or have reduced browse quality }\end{array}$ & $\begin{array}{l}\text { Stakeholders have a perception that } \\
\text { is formed in the absence of complete } \\
\text { participation in South African National } \\
\text { parks (SANParks) engagements through } \\
\text { a lack of interest, understanding of } \\
\text { the terms of reference of the existing } \\
\text { structure or park forum and manner in } \\
\text { which to engage with SANParks }\end{array}$ & $\begin{array}{l}\text { Tourism experience depends on how } \\
\text { often tourists see large mammals. This } \\
\text { depends on whether a tourist or large } \\
\text { mammal is at the same place at the same } \\
\text { time. Tourist space use is constrained } \\
\text { by existing road networks and timing of } \\
\text { drives that does not necessarily coincide } \\
\text { with how large mammals use the } \\
\text { landscape. This leads to tourists seeing } \\
\text { large mammals less often }\end{array}$ \\
\hline Prioritisation scale & Parts of the Addo Elephant National Park & $\begin{array}{l}\text { The region that the Augrabies Falls } \\
\text { National Park influences }\end{array}$ & Localised tourist viewing areas \\
\hline Rate of change & Fast & Fast & Unknown \\
\hline Measures: concern & Plant species richness & $\begin{array}{l}\text { Incidences of park activities influenced } \\
\text { by stakeholders }\end{array}$ & $\begin{array}{l}\text { Tourist experience through structured } \\
\text { interviews }\end{array}$ \\
\hline Measures: driver & Space use of mega-herbivores & $\begin{array}{l}\text { Perceptions of stakeholders through } \\
\text { structured interviews }\end{array}$ & Space use by tourists \\
\hline
\end{tabular}

that the degree of uncertainty associated with any particular TPC be classified along a continuum from empirical-based, through experience-based, to hypothetical situations. This will allow scientists to prioritise the TPCs that require more hard data, whilst managers develop confidence in the use of TPCs.

\section{Use of the TPC concept by other organisations}

Whilst SANParks has been concerned with managing ecosystems, using TPCs to measure unacceptable change, the South African Biodiversity Institute (SANBI) has been striving to maintain representative vegetation types by meeting national targets. These operational approaches apparently contradict one another - from the SANParks perspective the state of the system can vary whilst still retaining its essential structure and function, whilst SANBI's outlook was that at least a fixed amount of each representative unit needed to be 'conserved', although at a coarser national scale. Maintenance of representative vegetation types carries ecological non-realities and short-sightedness on the part of advisory ecologists. However, ongoing interactions between SANParks and SANBI have resulted in a growing realisation that 'thresholds' and 'targets' are similar constructs. Whilst SAM 'thresholds' delineate the boundaries of the desired state when within them, 'targets' define a trajectory towards a desired state or condition from the outside. This emerging understanding has resulted in SANBI proposing the use of national biodiversity thresholds in place of the national biodiversity targets, representing decision end-points based on unacceptable, but justifiable, system change.

\section{Challenges, uncertainties and the way forward}

In addition to demonstrating the advances that SANParks has made in its implementation of SAM, it is also useful to reflect on the challenges and uncertainties that constrain its development (see Jacobson et al. 2006). In doing so, we focus on three challenge areas that have emerged during the SMFs.

\section{Challenges involved in adopting the new non- equilibrium paradigm}

Possibly the most pervasive challenge to the implementation of adaptive management outside of the KNP is the institutional difficulty of shifting to the new ecological paradigm. Managers and scientists alike are faced with the daunting prospect of letting go of decades-old approaches to conservation management that involved intensive, largely command-and-control management (Rogers et al. 2000) of problem species based largely on agricultural principles such as carrying capacity. Moreover, this approach was underpinned by an equilibrium-based understanding of ecosystem dynamics. Adopting the non-equilibrium paradigm involves 'unlearning' all of these principles and learning a whole suite of new and unfamiliar terminology.

Whilst the use of stocking rates provided a simple formula with which to make decisions about wildlife management historically, the use of TPCs to inform management decisions has proven intangible to many managers beyond the KNP to date. And because TPCs were introduced to managers in the context of how to deal with flux, the non-equilibrium paradigm and adaptive management are still often used synonymously, rather than it being understood that adaptive management is merely the tool with which to address the complexity and uncertainty of non-equilibrium systems. Critics of the non-equilibrium paradigm are therefore quick to dismiss the use of TPCs to inform management decisions.

Finally, adoption of the non-equilibrium paradigm is constrained by pervasive perceptions amongst scientists and managers that small park size places limitations on ecosystem processes such that they cannot possibly operate 
in a similar manner to larger parks. SANParks now addresses this possible limitation by attempting to mimic such lost processes.

\section{Institutional constraints to implementing SAM}

Rogers (2003) has provided a comprehensive review of the major institutional constraints facing the implementation of SAM and we therefore do not attempt to repeat these here. Rather, we outline some additional constraints that have emerged during the implementation of SANParks' own adaptive planning and management process.

One of the key limitations to the successful use of SAM that has emerged during its development is reflected by the fact that conflicting objectives still manage to creep into parks' objectives hierarchies, placing serious limitations on achieving their mandates. We suggest that this is as a direct result of lack of buy-in to the prioritisation of its high level objectives on a departmental level during the adaptive planning process. This is particularly the case with nonbiophysical departments. Consequently, departmentalscale management priorities are not aligned with corporate strategies or values at a park level. In situations where a park must sustain itself with limited or no state subsidies, the upshot is that the objective associated with the best (often short-term) financial outcome most often receives the higher priority, despite the risks this creates for failing to address the remaining objective. The vision and mission for each park reflect its stakeholders' values, which, in turn, provide the rationale for the park's operating principles. Consequently, it should be possible to trace each and every management action back to stakeholder values through the park's objectives hierarchy. Apart from making future management decisions more defensible, this traceability of a shared value system also makes management decisions less prone to conflict amongst departments within a particular park. Without park-wide departmental involvement in the adaptive planning process, the successful implementation of SAM is severely compromised.

Feedback about what has been learnt through monitoring, research and management intervention is an essential component of SAM that allows conservation organisations to improve the outcomes of their biodiversity conservation mandate incrementally (see Cundhill \& Fabricius 2009; Duncan \& Wintle 2008). Although various performance evaluation and outcome assessment initiatives exist, SANParks still faces the challenge of adequately and timeously providing the necessary feedback in a format that ensures it will be useful and used. Incorporated into this feedback should be a mechanism that tracks the progress made with SAM explicitly at each stage of the adaptive management cycle, as well as across various scales within the organisation. Such a tracking system represents the institutional memory that is essential for adaptive learning.

Finally, a remaining challenge is to outline the possible management actions that can be undertaken once a TPC is reached and to do so pro-actively or strategically, rather than once the TPC has already been exceeded. Such strategic planning and weighing up of options is one requirement of SAM that has, as yet, not been explicitly incorporated into the adaptive planning and management process. Consequently, it has not yet fully matured in SANParks, and is one which, with adequate attention, should make the use of TPCs much more tangible to managers.

\section{Making SAM tangible to managers yet rigorous enough for scientists - The search for a 'requisite simplicity'}

Managers of complex systems complain that science delivers information that is not useful for implementation, often because it is cluttered with complicated detail. Stirzaker et al. (2010) suggest that identifying a 'requisite simplicity' (Holling 2001) may provide the tangibility that managers seek from science. A requisite simplicity attempts to discard some detail, whilst retaining conceptual clarity and scientific rigor, and therefore helps conservationists move to a new position where they can more usefully benefit from new knowledge (detail). Whilst the key elements of the requisite simplicity must be measureable, it is not falsifiable in the same sense as an experimental hypothesis (Stirzaker et al. 2010). The requisite simplicity does represent a conceptualisation of the problem and conservationists' measurements can show whether events are unfolding in a way that is consistent with this conceptualisation. It provides a basis for conservationists' actions, although they expect that, as context and values change and knowledge is gained, it will be superseded (Stirzaker et al. 2010). Our mechanism framework fulfils all of the requirements of this definition. We therefore suggest that, in addition to providing the critical links between management objectives and actions, this recent modification of the adaptive planning process also provides the sought after requisite simplicity.

\section{Conclusion}

This paper has outlined the development of SAM and its implementation beyond the KNP. We have done this primarily by discussing biophysical issues, but have also illustrated how we incorporate social factors into the case studies that we presented. We have also highlighted the areas that still require substantial development before the use of SAM within SANParks can be considered to be matured. We believe that these developments and deficiencies can provide useful lessons for other conservation agencies using adaptive management to achieve their conservation mandates. Establishing a forum for regular discourse between scientists and managers has been a key supplementation to the SAM process developed in the KNP. Through these SMFs the use of a framework that links the objectives hierarchy with operational endpoints has been developed. This ensures the identification of appropriate indicators for each TPC, whilst developing a joint mental model of the system between scientists and managers. TPC quantification beyond the KNP now requires attention and developing the concept of TPCs to incorporate such components as directionality and rate of change could benefit the SAM process throughout 
SANParks and internationally. Herein lies the importance of establishing and maintaining the SMFs, as these forums are structured to address all of the limitations identified above.

\section{Acknowledgments}

We gratefully acknowledge Mr Cillie Malan and Dr Harry Biggs for their contribution to this paper in the form of the evaluation of comparative risk assessment outlined in Box 1.

\section{References}

Biggs, H.C., 2003, 'Integration of science: Successes, challenges, and the future', in J.T. du Toit, K.H. Rogers \& H.C. Biggs (eds.), The Kruger experience. Ecology and management of savanna heterogeneity, pp. 469-487, Island Press, Washington DC.

Biggs, H.C., Ferreira, S.M., Freitag-Ronaldson, S. \& Grant-Biggs, R., 2011, 'Taking stock after a decade: Does the 'Thresholds of Potential Concern' concept need a socioecological revamp?', Koedoe 53(2), Art. \#1002, 9 pages. doi:10.4102/koedoe. v53i2.1002

Cundill, G. \& Fabricius, C., 2009, 'Monitoring in adaptive co-management: Toward a learning based approach', Journal of Environmental Management 90(11), 3205-3211. doi:10.1016/j.jenvman.2009.05.012, PMid:19520488

Duncan, D. \& Wintle, B.A., 2008, 'Towards adaptive management of native vegetation in regional landscapes' in C. Pettit et al. (eds.), Landscape analysis and visualisation. Spatial models for natural resource management and planning, Springer-Verlag $\mathrm{GmbH}$, Berlin.

Ferreira, S.M., Deacon, A., Sithole, H., Bezuidenhout, H., Deamane, E. \& Herbst, M., 2011, 'From numbers to ecosystems and biodiversity - a mechanism approach to monitoring', Koedoe 53(2), Art. \#998, 12 pages. doi:10.4102/koedoe.v53i2.998

Gaylard, A., Cadenasso, M. \& Pickett, S.T.A., in press, 'A conceptual framework for managing species as ecosystem drivers: Spatial and temporal heterogeneity of surface water and elephant impacts in Kruger National Park', BioScience.

Holling, C.S., 2001, 'Understanding the complexity of economic, ecological and social systems', Ecosystems 4, 390-405. doi:10.1007/s10021-001-0101-5
Jacobson, S.K., Morris, J.K., Sanders, J.S., Wiley, E.N., Brooks, M., Bennetts, R.E., et al., 2006, 'Understanding barriers to implementation of an adaptive land et al., 2006, 'Understanding barriers to implementation of an adaptive land
management program', Conservation Biology 20(5), 1516-1527. doi:10.1111/ management program', Conservation Biology
j.1523-1739.2006.00476.x, PMid:17002769

Lindenmayer, D.B. \& Likens, G.E., 2009, 'Adaptive monitoring: A new paradigm for long-term research and monitoring', Trends in Ecology and Evolution 24(9), 482-486. doi:10.1016/j.tree.2009.03.005

Martin, J., Runge, M.C., Nichols, J.D., Lubow, B.C. \& Kendall, W.L., 2009, 'Structured decision making as a conceptual framework to identify thresholds for conservation and management', Ecological Applications 19(5), 1079-1090. doi:10.1890/080255.1, PMid:19688917

McKinsey \& Company, 2002, SANParks and McKinsey Final Meeting Report, following strategic review, SANParks, Skukuza.

Pickett, S.T.A., Cadenasso, M.L. \& Benning, T.L., 2003, 'Biotic and abiotic variability as key determinants of savanna heterogeneity at multiple spatio-temporal scales', key determinants of savanna heterogeneity at multiple spatio-temporal scales', management of savanna heterogeneity, pp. 22-40, Island Press, New York.

Pickett, S.T.A., Kolasa, J. \& Jones, C.G., 2007, The nature of theory and the theory of nature, 2nd edn., Academic Press Inc., San Diego.

Rogers, K.H., 2003, 'Adopting a heterogeneity paradigm: Implications for biodiversity management in protected areas', in J.T. du Toit, K.H. Rogers \& H.C. Biggs (eds.), The Kruger experience. Ecology and management of savanna heterogeneity, pp. 41-58, Island Press, New York.

Rogers, K.H., Roux, D. \& Biggs, H., 2000, 'Challenges for catchment management agencies: Lessons from bureaucracies, business and resource management', Water SA 26(4), 505-511.

Rogers, K.H. \& Sherwell, T., 2008, A framework for developing and implementing management plans for South African National Parks, viewed n.d., from http:// www.sanparks.org/parks/kruger/conservation/scientific/key_issues/plans/ adaptive/default.php

Stirzaker, R., Biggs, H., Roux, D. \& Cilliers, P., 2010, 'Requisite simplicities to help negotiate complex problems', AMBIO: A Journal of the Human Environment 39(8), 600-607.

Van Wilgen, B.W., Trollope, W.S.W., Biggs, H.C., Potgieter, A.L.F. \& Brockett, B.H., 2003, 'Fire as a driver of ecosystem variability', in J.T. du Toit, K.H. Rogers \& H.C. Biggs (eds.), The Kruger experience. Ecology and management of savanna heterogeneity, pp. 149-170, Island Press, New York.

Venter, F., Naiman, R.J., Biggs, H.C. \& Pienaar, D.J., 2008, 'The evolution of conservation management philosophy: Science, environmental change and social adjustments in Kruger National Park', Ecosystems 11, 173-192. doi:10.1007/s10021-0079116-x 